\title{
Influence of gender and locality on effectiveness of life skills education among students of senior secondary school in Jaipur district
}

\author{
SIDDHI GOYAL AND RUBY JAIN
}

Received: 02.01.2016; Revised: 23.03.2016; Accepted: 08.04.2016

See end of the paper for authors' affiliations SIDDHI GOYAL

Department of Home Science, University of Rajasthan, JAIPUR (RAJASTHAN) INDIA

Email : siddhugoyal91@ gmail.com

\begin{abstract}
Life skill refers to a positive behaviour, that encompasses a mix of knowledge, behaviour, attitude and values and designates the possession of certain skills and know how to do something positively, or reach a goal. Life skills education frame work provides the praxis for addressing the core concerns as well as aspirations of the adolescents and the youth of today's India. Life skills were differing to men to men. Life skills also influence by gender and locality also. A life skill for urban men was different from men living in rural areas. The main objective of present study was to examine the role of gender and geographical location in the effectiveness of Life Skills Education. The study was conducted on 2 urban and 2 rural blocks of Jaipur district. A sample of 200 male and 200 female adolescents studying in government schools of Jaipur District were selected through multistage sampling. The data was collected with the help of LSAS scale. Results indicate that the life skills were improved after the classroom learning of the subject among both boys and girls and urban and rural students. In the beginning of the course all students whether boy and girl belonging to urban and rural background were possessing the similar level of LS or LS's were at the same platform but variations were seen after the formal teaching of LS. But after completion of the subject significant difference was found in both boys and girls students and urban and rural students. But yet girls had better improvements in life skills as compare to boy's students and difference among them was significant but rural and urban students LS's did not show significant difference, hence geographical locality no more remains a constraint in the effectiveness of LSE.
\end{abstract}

KEY WORDS: Gender, Government schools, Life skills education, Locality

- HOW TO CITE THIS PAPER : Goyal, Siddhi and Jain, Ruby (2016). Influence of gender and locality on effectiveness of life skills education among students of senior secondary school in Jaipur district. Asian J. Home Sci., 11 (1) : 29-34, DOI: 10.15740/HAS/AJHS/11.1/29-34. 